\section{ambient \\ SCIENCE \\ Vol. 05(Sp1):24-27 \\ Year 2018}

\title{
Spiritual Intelligence and Self-efficacy: An attempt to Establish a Relationship among Hospitalized Patients Suffering from Cancer in Tehran University of Medical Sciences' Hospitals of Iran
}

\section{Sara Moghaddam', Fatemeh Golestan², Sakineh Ramezanli* ${ }^{\text {* }}$ Mojtaba Zeinijahromi ${ }^{1}$}

'Department of medical-surgical Nursing, Medical Ethics Research Center, Jahrom University of Medical Sciences, Jahrom, Iran

${ }^{2}$ Department of of crtical care Nursing, Medical Ethics Research Center, Jahrom University of Medical Sciences, Jahrom, Iran

Study Area: Tehran, Iran

Coordinates: $28^{\circ} 30^{\prime} 0^{\prime \prime N}$; $53^{\circ} 33^{\prime} 38^{\prime \prime E}$

Key words: Quality of Life, Self efficacy, Health recovery

Received permission from the Ethics Committee of Tehran University of Medical Sciences (9111196028-114946) \& the necessary referrals from the relevant hospitals.

\section{Introduction:}

Today, universally cancer diseas is one of the major causes of death (Kiaei et al., 2016). It is one of the disorders that affect all the aspects of a person's life, such as occupation, economic, social, family status, and various aspects of the quality of life, including mental status, mental health, selfefficacy and sexual function (Dehkordi \& Shaban, 2004). To take care of the patient in a comprehensive way, the total size of such dimensions must be considered (Rezaei et al., 2009). The spiritual dimension of man as in biological, psychological, and social values keeps a particular importance (Rahnama et al., 2012). The importance of spirituality and spiritual growth in humans over the past decades have attracted the attention of psychologists and mental health professionals (Hoseindokh et al., 2013). World Health Organization, and other relevant organizations have also reviewed their definitions in relation to the existential dimensions of mankind, and in addition to the physical, psychological, and social ones, the fourth dimension i.e., the spiritual dimension in human development and evolution (Sharafi et al., 2008). In stressful situations, especially due to health-related issues, spirituality acts a major role for relief (Koenig, 2004). Patients whose spiritual wellbeing is strengthened can effectively adapt to their illness and even successfully

\section{Abstract}

Spiritual intelligence is considered as a higher dimension of intelligence that activates the qualities and capabilities of individual beliefs in various fields, especially the individuals' capacity to deal with the difficulties and adapting to changes. However, self-efficacy facilitates the improvement of health in cancer patients. This study was carried out to identify the spiritual intelligence relationship with self-efficacy on 200 cancer patients by using simple random sampling method. The study was based on a series of a questionnaire on demographic information, the spiritual intelligence. The results showed that there is a statistically significant and direct relationship between spiritual intelligence and self-efficacy in patients with cancer exist. It suggests that by paying attention towards spiritual intelligence and augmentation of such factors in those patients an improvement in health could be expected.

recover from their illness (Lin \& Bauer-Wu, 2003). For cancer patients who are at the end of their illness, spiritual and religious calm may even be even more important than physical and psychological well-being (Rezaei et al., 2009). Because, spiritual intelligence can give people peace, especially in stressful situations (Bayrami et al., 2014). Spiritual intelligence combines the structures of spirituality and intelligence into a new structure and represents a set of capabilities especially of spiritual resources that their application in daily life can increase the adaptability of the individual and enable the person to alter and evolve (Hamid et al., 2012). The results of most researches have pointed out the role of spiritual intelligence and spirituality in health related psychological issues, including self-eff icacy. Self-efficacy is an important internal agent for long-term control of chronic diseases. Strengthening and paying attention to the self-efficacy feature in cancer patients is very important (Shoakazemi \& Momeni, 2010). Among the mechanisms of influence on oneself, none is more important and more comprehensive than the belief in selfefficacy (Esmaeli et al., 2012). Individuals who believe in their eff iciency are struggling to overcome obstacles and difficulties (Abdollahi, 2006). Bandura (1986) states that self-efficacy creates a person's confidence for successful 
performance. A person with low self-efficacy in a given position is likely to avoid hard-working, and has less desire and commitment for goals. While someone with high selfefficacy in a given position does things that are more challenging. He tries to overcome difficult situations and has more commitment for goals (Zimmerman, 2000). The results of Muris (2002) examined the relationship between the self-efficacy of emotional disturbance symptoms. The results showed that low level of self-efficacy were associated with a high level of anxiety/psychosis, anxiety disorder and depression symptoms. The overall score of autoimmunity has a negative relationship with anxiety/psychosis and depression symptoms (Fahimi, 2009). According to Arnstein et al., (1999), self-efficacy in pain relief plays a moderating role and affects the outcome of treatment (Pecukonis, 2009).

Shoakazemi \& Momeni (2010) compared and concluded the eff icacy and empowerment of healthy and breast cancer women a positive and significant relationship between self-eff icacy and empowerment and there was a significant difference between the two groups based on self-efficacy and level of ability There was. ParsaYekta et al. (2017), in a study on the relationship between emotional needs and self-efficacy in cancer patients reported a significant negative correlation between the overall score of self-efficacy and emotional needs. Thus by increasing the emotional needs of the patients, it reduces their self-efficacy and, consequently, increases the incidence and recurrence of the symptoms of the disease. Therefore, in order to reduce emotional needs and improve self-efficacy, more precise planning of educational and support interventions is needed (ParsaYekta et al., 2017). Considering that in our society the concept of quality of life and the factors affecting it Including self-employment has decreased, recognizing these factors helps the health and community health community to organize their activities to improve the quality of life and improve the quality of life, especially nurses who have close links with these patients. By identifying these factors, they can take steps to correct these problems (Dehkordi \& Shaban, 2004). Self-efficacy in cancer patients is of paramount importance in helping them to cope effectively with the disease and control symptoms, treatments, physical consequences, and psychosocial effects. It is important to examine the factors which are associated with this variable and improve it for such patients. On the other hand, spiritual intelligence is considered as one of the known types of intelligence and the foundation of individual beliefs in various fields, especially the provision and elevation of mental, individual and social health, which gives the person a capacity to deal with the diff iculties and adapt to changes. . But as one can evaluate from the above mentioned several studies, which have been done on autoimmunity and its impact on improving health and improving the quality of life of patients with health. Also, there was some research on spiritual intelligence and its impact on life expectancy and quality of life in cancer patients, but they didn't compare the relationship between these two factors. Therefore, we aimed to establish the relationship between spiritual intelligence and Self-efficacy in patients suffering from cancer diseases.

\section{Methodology:}

The present study is a descriptive-analytic correlation study conducted in some selected hospitals of Tehran University of Medical Sciences, year 2014. Systematically the sample size was estimated to be 200 who were the cancer patients referred to Shariati Hospitals, Valiasr Hospital and Cancer Institute of Imam Khomeini Hospital affiliated to Tehran University of Medical Sciences. The patients were well-diagnosed cancer disease (at least one month after) aged between 15 to 65 years. The subjects were informed and consent taken for the completion of the study. The patients with mental illness (as per records), leaving the study, given incomplete answers were excluded. From each hospital, we examined 70 patients using available sampling. The data gathering tool was three sets of questionnaires; i) demographic information which included age, sex, marital status, educational level, employment status, economic status, type of disease, duration of diagnosis and current treatment, ii) Spiritual Intelligence Questionnaire, King. This set of the questionnaire was having 24 items with the options of"totally disagree" to "totally agree" and ranked 1 to 5 . The scale is based on the Likert five-point spectrum. The overall scale score (spiritual intelligence), was ranged from 24 to 120 . A higher score indicated a high level of spiritual intelligence and lower score indicated a low level of spiritual intelligence in theindividuals. Reliability of Spiritual Intelligence Scale was already applied earlier successfully by various researchers in this regard (Esmaeli et al., 2012; Abdollahi \& Ebrahim, 2007; Zimmerman, 200o). In our study, content validity method was used to determine the validity of the tool which was evaluated and updated from the relevant academician so that no one should not face any problem while handling the content of the tool. The questionnaires were completed through selfreport or by the researcher (for illiterate patients). Data were analyzed by SPSS software (version-2o). Descriptive statistics (mean, percentage, and standard error) were used for descriptive statistics. Pearson correlation coefficient, Spearman correlation coefficient, and the independent"t-test"were used.

\section{Results:}

Among the 200 cancer patients, who had participated in our study, the majority of them are in the age group of 25-34 years, male (51\%), married ( $74.5 \%)$, and diploma education 
(35.5\%). The majority of them reported in terms of employment status as a housekeeper and in terms of economic status as inadequate (59\%). According to our results, the type of disease was the lowest frequency towards laryngeal cancer and the highest frequency was of leukemia, (70\%) equivalent to $35 \%$ of the population. Based on the results, more than $57.5 \%$ of the patients were using chemotherapy to treat their illness (Table-1).

Table-1: Distribution of the characteristics of individual cancer patients under treatment from some selected hospitals (2014)

\begin{tabular}{lll}
\hline Demographic characteristics & Frequency \\
\hline Sex & Women & $(49) 98$ \\
Age & Men & $(51) 102$ \\
& $15-24$ & $27(13 \cdot 5)$ \\
& $25-34$ & $53(26.5)$ \\
& $35-44$ & $23(46)$ \\
Marital Status & $45-54$ & $21.5(43)$ \\
& $55-65$ & $15 \cdot 5(31)$ \\
Education level & Single & $23 \cdot 5(47)$ \\
& Married & $149(74 \cdot 5)$ \\
& Widow/divorced & $4(2)$ \\
& Illiterate & $18(9)$ \\
Job & Guide & $65(32.5)$ \\
& Diploma & $71(35 \cdot 5)$ \\
& Academic & $46(23)$ \\
& Housewife & $78(39)$ \\
Economic situation & Employed & $66(33)$ \\
Current treatments & Sufficient & $41(20.5)$ \\
Status & Rot enough & $15(7 \cdot 5)$ \\
& Chemotherapy & $82(41)$ \\
& Surgery & $118(59)$ \\
& Surgery \& chemotherapy & $16(8)$ \\
& & $115(57 \cdot 5)$ \\
& & $60(30)$ \\
& &
\end{tabular}

The results of our study showed that out of the total 200 respondents, $44.5 \%$ are the most spiritual intelligence, $18.5 \%$ had the least spiritual intelligence, and the rest $37 \%$ did not respond in this regard. Further, $12 \%$ had the highest self-efficacy and 10\% had the lowest self-efficacy and the rest had a moderate overall self-eff icacy (Table 2 ).

Table-2: Frequency distribution based on variables of spiritual intelligence and general self-efficacy

\begin{tabular}{lll}
\hline Variable & points $\%$ & Percentage of people \\
\hline Spiritual Intelligence & & \\
Completelyopposed & 20 & 6 \\
Against & 40 & 12.5 \\
Nocomments & 60 & 37 \\
agreed little & 80 & 29 \\
Completely agree & 100 & 15.5 \\
Public self-efficacy & & \\
Notatall & 25 & 10 \\
Sometimes & 50 & 31.5 \\
Most of the time & 75 & 46.5 \\
Always & 100 & 12
\end{tabular}

The results showed that the highest and lowest score towards spiritual intelligence was 117 and 71, respectively with Mean \pm SE given below. In addition, the lowest total self-eff icacy score was 13 and the highest score was 40, the Mean \pm SE of which are given below. Correlation between spiritual intelligence variables with general self-eff icacy of patients participating in the study was used by Pearson correlation test. There was a correlation between these two variables $(\mathrm{p}<0.000$ and $\mathrm{r}=0.681)$. (Table -3 )

Table-3: Mean+SE and correlation between two variables

\begin{tabular}{|c|c|c|c|c|c|c|}
\hline Mean & SE & $\mathrm{p}$ value & Sig.(p) & Max & Min & K-S amount \\
\hline \multicolumn{7}{|c|}{ Public self-efficacy } \\
\hline 27.16 & 0.4 & $<0.05$ & 0.23 & 40 & 13 & 0.391 \\
\hline \multicolumn{7}{|c|}{ Spiritual Intelligence } \\
\hline 97.22 & 0.67 & $<0.05$ & 0.356 & 117 & 71 & 0.356 \\
\hline
\end{tabular}

\section{Discussion:}

Our research showed that there was no relationship between demographic characteristics and spiritual intelligence in relation to the relationship between demographic characteristics and each of the studied variables like spiritual intelligence and self-efficacy. But there was a correlation between sex, employment, and education with the positivity and self-efficacy and agerelated relationship, and it strengthens Kiaei et al. (2016), which reported that self-eff icacy score in higher educated and economic groups was better. Further, as per our results, there was a direct relationship between spiritual intelligence and general self-efficacy in the patients suffering from cancer, so that self-efficacy increases with increasing spiritual intelligence of respondents. Esmaeli et al (2012) reported a significant correlation existing between self-efficacy and spiritual intelligence and with increasing spiritual intelligence, self-efficacy also increases, and our results supports their reports. As per Golchin \& Sanjar (2012)'s report on Golestan province employees and managers, a positive and significant relationship existed between spiritual intelligence and self-efficacy. Adegbola (2011) employed the same in the sickle cell disease patients and reported almost the same results. Spiritual intelligence can be considered as the highest existential intelligence that creates a new and positive attitude towards oneself, others, and the world around it. Considering the fact that self-efficacy refers to one's own abilities and skills, it can be said that the high spiritual intelligence in a person causes a person to have a positive look at himself and can do it while It's good to use your skills and thus high spiritual intelligence would have high self-efficacy.

According to Woby et al. (2007) the self-efficacy towards the pain relief with experience of pain and painrelated disability plays a moderating role and affects the 
outcome of the treatment, resulting in self-efficacy that never leave the person losing mobility and dynamism. Individuals with poor self-efficacy do not exert any effort to cope with the problems, they fail to feel immediately when they encounter barriers, but those with high selfefficacy believe that they can deal with barriers of life effectively. As a result, it can be stated that in cases of illness, patients have the most ability to consider critical situations as less threatening and, consequently, this causes gives success in recovery.

In general, the findings of our study showed that there was a positive and significant relationship between spiritual intelligence and self-efficacy. As self-efficacy increased, with increasing spiritual intelligence. Infact cancer disease itself harm the physical, psychological, social, economic and family life of the patient. In addition, long admissions, frequent visits to the doctor, various treatments, complications and high treatment costs increase anxiety, reduce motivation and ease the patients. Thus, the use of spiritual intelligence and other factors that enhance self-efficacy could be beneficial for the health-related issues in cancer patients and facilitates health improvement in them. Nurses can also increase the self-efficacy and other variables that affect the disease through spiritual intelligence training as a growth factor in cancer and other related serious patients. However, our study could be used as a baseline research for the further relevant studies in the coming future.

\section{Acknowledgment:}

The present study is a part of a dissertation of a master's degree of Tehran University of Medi. Sci. conducted under the direction of Prof. Dr. Sohrab, Dr. Zohreh Parsa Yekta. Thanks to Tehran University of Med. Sci. for provided funding and staff \& authorities of Shariati, Valiasr, and Imam Khomeini Hospital including all the patients and people for cooperation.

\section{References:}

Abdollahi, B, (2006): The role of self-efficacy in employee empowerment. Tadbir Mon. Period., 17(168):35-40

Adegbola, M. (2011): Spirituality, self-efficacy, and quality of life among adults with sickle cell disease. South Online J. Nurs. Res., 11(1)pii: 5 .

Arnstein, P, Caudill, M., Mandle, C.L., Norris, A. \& Beasley, R. (1999): Self eff icacy as a mediator of the relationship between pain intensity, disability and depression in chronic pain patients. Pain, $80(3): 483-491$.

Bandura, A. (1986): Social Foundations of Thought and Action: A Social Cognitive Theory. Pub. by: Englewood Cliffs, N.J.: Prentice-Hall.

Bayrami, M., Movahedi, Y. \& Movahedi, M. (2014): The Role of Spiritual Intelligence in Perceived Stress, Anxiety and Depression of Lorestan Medical University Students. L. Babol Uni. Med.Sci., 16(1):56-62.

Dehkordi, A. \& Shaban, M. (2004): Assessing relationship between cancer variables and quality of life in cancer patients under chemotherapy in Tehran. I. Shahrekord Uni. Med. Sci., 6(4):63-71. (Persian).
Esmaeli, P.A.Z., Soheila, M., Zahra, S. \& Mahmoud, A. (2012): Assessment of correlation between self- eff icacy and spiritual intelligence of family caregivers of elderly patient with Alzheimer in Tehran 1391. Med.Figh Quart.,. 4(11-12):151-166.

Fahimi, H. (2009): Study relationship between self efficacy \& well- being in students of Yazd University. Thesis submitted for the degree of MA in Alzahra University (1388).

Golchin, M. \& Sanjari, A. (2012): Investigating the relationship between spiritual intelligence and self-efficacy of employees: a case study of Golestan province education organization. Org. Behav. Stud., 3:53-66.

Hamid, N., Keykhosravani, M., Babamiri, M. \& Dehghani, M. (2012): The relationship between mental health and spiritual intelligence and resilience in Kermanshah University of Medical Sciences. Lntashapir J. Health. Res.,7(2):331-338.

Hoseindokht, A., Ashtiani, F.A., Taghizadeh, M.E. (2013): The Relationship of Spiritual Intelligence and Spiritual Wellbeing with Life Quality and Marital Satisfaction. Ravanshenasi-va Din, 6(2):59-77.

Kiaei, M., Ferdosi, M., Moradi, R, Chelongar, Q., Ahmadzadeh, M.S. \& Bahmanziari, N. (2016): Association between selfefficacy and quality of life in women with breast cancer undergoing chemotherapy. J. Qazvin Uni. Med. Sci., 20(2):5865 .

Koenig, H.G. (2004): Religion, Spirituality, and Medicine: Research Findings and Implications for Clinical Practice. South. Med.J., 97(12):1194-1200.

Muris, P. (2002): Relationships between self-efficacy and symptoms of anxiety disorders and depression in a normal adolescent sample. Personal. Indiv. Differ., 32:337-348

Lin, H.R. \& Bauer-Wu, S.M. (2003): Psycho-spiritual well-being in patients with advanced cancer: an integrative review of the literature. JAdv Nurs., 44(1):69-80.

Parsa-Yekta, Z., Shahsavari, H., Ramezanzade- Tabriz, E. \& Yekaninejad, M.S. (2017): Relationship between Emotional Needs and the Level of Self-Efficacy of Cancer Patients Admitted to Omid Hospital in Mashhad in 2014. LRafsanjan Uni.Med.Sci.,15(8):726-38.

Pecukonis, E.V. (2009): Physical Self- efficacy and Alexithymia in Women with Chronic Intractable Back Pain. Pain Manag Nurs., 10(3):116-123.

Rahnama M, Khoshknab, M.F., Madah, S.S.B., Ahmadi, F. (2012): Cancer patients' perception of spiritual care. Iran. J. Med. Ethics His. Med., 5(3):64-80.

Rezaei, M., Seyed Fatemi, N., \& Hoseyni, F. (2009): Spiritual health in cancer patients receiving chemotherapy. J. Nurs. Midwifery. 14(3-4):33-39.

Sharafi, E., Mehrabi, H., Kalantari, M. \& Meftagh, D. (2008): Developing and Analyzing the Psychometric Properties of Spiritual Attitude Questionnaire in Isfahan University Students. Biquart. J.Stud. Islam Psycho., 1(2):59-78.

Shoaakazemi, M. \& Momenijavid, M. (2010): The Relationship Between Quality of Life and Life expectancy in post-operative cancer patients. J. Breast Cancer Iran, 2(3\&4):20-27.

Woby, S., Urmston, M. \& Watson, P. (2007): Self-efficacy Mediates the Relation between Pain-related fear and Outcome in Chronic Low Back Pain Patients. Eur. J. Pain,11(7):711-718.

Zimmerman, B.J. (200o): Self-efficiency: an essential to learn. Contem. Edu. Psychol., 25(1):82-91. 